\title{
Assessment of psychosocial health during COVID-19 Pandemic among Indian adults
}

\author{
Khushboo Juneja ${ }^{1}$, Amit Singh Pawaiya ${ }^{2}$, Neeti Purwar ${ }^{3}$, Tuhina Shree ${ }^{4}$, Seetharamiah Nagesh ${ }^{5}$, Neeraj \\ Pal Singh ${ }^{6}$
}

${ }^{1}$ Assistant Professor, Department of Community Medicine, School of Medical sciences and Research., Sharda University, Gautam Buddh Nagar, Uttar Pradesh, India; ${ }^{2}$ Associate Professor, Department of Community Medicine, School of Medical sciences and Research., Sharda University, Gautam Buddh Nagar, Uttar Pradesh, India; ${ }^{3}$ Assistant Professor, Department of Community Medicine, School of Medical sciences and Research., Sharda University, Gautam Buddh Nagar, Uttar Pradesh, India; ${ }^{4}$ Senior Tutor, Department of Community Medicine, School of Medical sciences and Research., Sharda University, Gautam Buddh Nagar, Uttar Pradesh, India; ${ }^{5}$ Professor \& HOD, Department of Community Medicine, School of Medical sciences and Research., Sharda University, Gautam Buddh Nagar, Uttar Pradesh, India; ${ }^{6}$ Biostatistician, Department of Community Medicine, School of Medical sciences and Research., Sharda University, Gautam Buddh Nagar, Uttar Pradesh, India

\begin{tabular}{|c|c|c|c|c|c|c|c|}
\hline Abstract & Introduction & Methodology & Results & Conclusion & References & Citation & Tables / Figures \\
\hline \multicolumn{8}{|c|}{ Corresponding Author } \\
\hline \multicolumn{7}{|c|}{$\begin{array}{l}\text { Tuhina Shree, Department of Community Medicine, School of Medical sciences and Research, } \\
\text { Sharda University, Gautam Buddh Nagar, Uttar Pradesh, India } \\
\text { E Mail ID: tuhinashree07@gmail.com }\end{array}$} & 回都回 \\
\hline \multicolumn{8}{|l|}{ Citation } \\
\hline \multicolumn{8}{|c|}{$\begin{array}{l}\text { Juneja K, Pawaiya AS, Purwar N, Shree T, Nagesh S, Singh NP. Assessment of psychosocial health during COVID- } \\
19 \text { Pandemic among Indian adults. Indian J Comm Health. 2020;32(4):713-716. } \\
\text { https://doi.org/10.47203/IJCH.2020.v32i04.017 }\end{array}$} \\
\hline
\end{tabular}

\section{Article Cycle}

Received: 13/10/2020; Revision: 21/11/2020; Accepted: 19/12/2020; Published: 31/12/2020

This work is licensed under a Creative Commons Attribution 4.0 International License.

\section{Abstract}

Background: Lockdown due to COVID-19 pandemic has an effect on all the dimensions of health. Previous epidemics and pandemics had made a catastrophic impact on mental wellbeing of general public. Methods: A cross sectional online study was carried out in the month of May. Data collection was done using Google form which contained semi-structured questionnaire. Results: Total 450 individuals participated in the study. About one-fourth of the participants felt depressed (28.9\%) listening to the constant news updates about corona virus. Almost half of participants $(50.7 \%)$ had altered eating habits. Nearly one-third of the participants had difficulty (35.1\%) in falling asleep. Conclusion: This study reports that there is a negative impact on psychosocial health of general public who were confined to their homes due to COVID-19 pandemic in the country.

\section{Keywords}

COVID-19; Psychosocial Health; Pandemic

\section{Introduction}

In December 2019, a novel SARS-CoV2 was reported in Wuhan City of Hubei province of central China. A cluster of about 40 cases of pneumonia of unknown aetiology was identified, some of the patients being traders in the Huanan Seafood market. The concerned market in Wuhan was closed on 1st January 2020 for sanitization and disinfection.(1) On 25th March, 2020 our honourable Prime Minister, 'Narendra Modi announced a 21-day complete lockdown in 1st phase across the India to control the spread of SARS-CoV2. As on 12th Oct, 2020, there were 861853 active cases, 6149535 
cured or discharged cases and 109150 deaths according to official government reports.(2)

Social isolation, due to lack of contact with society, can lead to a wide range of consequences mainly on psychological wellbeing of an individual. Previously conducted epidemiological studies reported depression, anxiety, negative psychological effect, panic attack, psychomotor excitement, psychotic symptoms, delirium, and even suicidal tendency among the survivors of the SARS epidemic. $(3,4)$

\section{Aims \& Objectives}

To assess impact of COVID-19 pandemic on psychosocial health

\section{Material \& Methods}

This cross-sectional study was carried out in May 2020 for a period of four days. The information was collected through online semi-structured questionnaire which was developed using Google form with consent form attached in the beginning. Data was collected regarding socio-demographic characteristics and Psychosocial health from the participants. Study participants were of age 18 years and above, having internet on their mobile phones and/or WhatsApp users and those who were able to read and write in English. Total 450 responses were received. Ethical clearance was taken from Institution Ethics Committee. Data was entered and analysed using SPSS version 21. Statistics used to report the findings were frequency and percentage.

\section{Results}

As shown in (Figure 1), nationwide, a total 450 individuals, consented to participate in the study. Maximum number of participants were from Uttar Pradesh (37.1\%) followed by New Delhi (23.1\%).

The mean age of the participants was 29.2 years (S.D $=10.06$ ) ranging between 18 to 71 years. Male (52.9\%) and female (47.1\%) gender was almost equally distributed among study population. Almost half of the participants belonged to nuclear family (44.9\%). The education level of the study participants was on the higher side as nearly one-third of the participants were graduates (37.1\%) and postgraduates (31.1\%). Students, home makers, retired and those who were out of work were grouped together as unemployed and formed more than half $(54.7 \%)$ of the study participants while the remaining were employed (45.3\%). During the lockdown period, out of the total 204 participants who were employed almost half of the participants worked from home (53.4\%). Majority of participants were health care professionals (63.6\%).

(Table 1) highlights the psychosocial health impact due to COVID -19 pandemic. More than one-fourth of the participants felt that incessant news and updates of corona on every platform makes them feel sad and depressed (28.9\%). Almost half of participants had no change in eating habits (49.3\%) during last 15 days while the remaining study subjects either were eating more $(27.8 \%)$ than normal or eating lesser $(22.9 \%)$ than the amount they usually consume. Almost two-third of participants had no difficulty (64.9\%) in falling asleep however, $4 \%$ participants always had sleeping difficulty due to constant worrying about pandemic. Nearly one-third (30\%) of the participants observed that they never felt scared by social media posts on COVID-19 pandemic in last 5 weeks nonetheless, social media feeds had freaked out the remaining participants in varying degree (occasionally sometimes, often and always). Majority of study subjects strongly disagreed (32.7\%) with the statement that social relations with the health care workers should be cut off as they act as a possible source of COVID-19 transmission. In an open-ended question participant were asked about how do they keep themselves occupied during lockdown. Social media (69.6\%) and television (65.3\%) were the most commonly employed method to stay engaged.

\section{Discussion}

Psychosocial health is impacted to a great extent due to lockdown imposed to curb spread of COVID-19 worldwide. Hence this study was conducted to get an insight into the health of general public due to this pandemic.

In our study the majority of the participants in our study had above high school education level. This is similar to the study done by D. Roy, et al. where the lowest educational level was observed to be standard 10th and the highest qualification of more than $90 \%$ of the population was graduation and above.(5) This should be by default as only those individuals who could read English and use smartphones were included in the study.

Almost half of the study participants in the present study reported either eating much more or much less than what they eat normally. This is in line with a survey conducted among participants from the United States and Netherlands which reported a 
wide range of eating disorders among its participants during COVID-19 Pandemic. (6)

In our study, sleep was not affected (64.9\%) for majority of the participant due to the pandemic. This was in contrast to study done by Chakraborty et al in which near about one-third of the respondents reported of having disturbed sleep in the past 2 weeks. This was also in excess of the reported prevalence of nonorganic insomnia in a community sample.(7)

According to our study $29.8 \%$ of participants observed that they never felt scared by social media posts on COVID-19 pandemic in last 5 weeks whereas only $3.8 \%$ of total study population were always scared by social media posts on COVID-19 pandemic in last 5 weeks. Media influences the psychological well-being and adds to the level of anxiety. The swine flu pandemic of 2009-2010, which resulted in high mortality worldwide also caught global media attention and evoked anxiety among the public significantly (Everts, 2013).(8)

It has been identified that there was a positive correlation between public anxiety and the media coverage during outbreak of SARS (Xie, et.al, 2011).(9)Social media usage and Television were most often used medium to stay mentally engaged during social isolation by our study participants. Government of India has issued a number of documents, audio-visuals and guidelines recommending on how to handle social isolation and emotional problems during pandemic. Also, a tollfree number has been launched for advice on psychosocial health to the general public.

\section{Conclusion}

The study revealed that COVID-19 pandemic is creating psychological distress among the individuals. Moreover, efforts should be put to raise the awareness to counterattack stigma against healthcare workers. There is a need to promote awareness regarding infodemic that is going in parallel with COVID-19 pandemic to promote mental wellbeing of individuals.

\section{Limitation of the study}

Study was conducted among mobile phone users and people who could understand and write in English. This potentially affected the generalizability of the study.

\section{Authors Contribution}

All the authors have contributed at various stages of composition of the final manuscript.

\section{Acknowledgement}

We would like to express our gratitude to all the participants for their co-operation.

\section{References}

1. Li Q, Guan X, Wu P, Wang X, Zhou L, Tong $Y$, Ren R, Leung KSM, Lau EHY, Wong JY, Xing X, Xiang N, Wu Y, Li C, Chen $Q$, Li D, Liu T, Zhao J, Liu M, Tu W, Chen C, Jin L, Yang R, Wang Q, Zhou S, Wang R, Liu H, Luo Y, Liu Y, Shao G, Li H, Tao Z, Yang Y, Deng Z, Liu B, Ma Z, Zhang Y, Shi G, Lam TTY, Wu JT, Gao GF, Cowling BJ, Yang B, Leung GM, Feng Z. Early Transmission Dynamics in Wuhan, China, of Novel Coronavirus-Infected Pneumonia. N Engl J Med. 2020 26;382(13):1199-1207. doi: 10.1056/NEJMoa2001316. Epub 2020 Jan 29. PMID: 31995857; PMCID: PMC7121484.[PubMed]

2. Government of India. Ministry of Health and family welfare. Available from: https://www.mohfw.gov.in/ . [Last accessed on 22 Dec 2020].

3. Maunder R, Hunter J, Vincent L, Bennett J, Peladeau N, Leszcz M, Sadavoy J, Verhaeghe LM, Steinberg R, Mazzulli T. The immediate psychological and occupational impact of the 2003 SARS outbreak in a teaching hospital. CMAJ. 2003 13;168(10):1245-51. PMID: 12743065; PMCID: PMC154178.[PubMed].

4. Lee AM, Wong JG, McAlonan GM, Cheung V, Cheung C, Sham PC, Chu CM, Wong PC, Tsang KW, Chua SE. Stress and psychological distress among SARS survivors 1 year after the outbreak. Can J Psychiatry. 2007;52(4):233-40. doi: 10.1177/070674370705200405. PMID: 17500304.[PubMed].

5. Roy D, Tripathy S, Kar SK, Sharma N, Verma SK, Kaushal V. Study of knowledge, attitude, anxiety \& perceived mental healthcare need in Indian population during COVID-19 pandemic. Asian J Psychiatr. 2020;51:102083. doi: 10.1016/j.ajp.2020.102083. Epub 2020 Apr 8. PMID: 32283510; PMCID: PMC7139237.[PubMed].

6. Termorshuizen JD, Watson HJ, Thornton LM, Borg S, Flatt RE, MacDermod CM, Harper LE, van Furth EF, Peat CM, Bulik CM. Early impact of COVID-19 on individuals with selfreported eating disorders: A survey of $\sim 1,000$ individuals in the United States and the Netherlands. Int J Eat Disord. 2020;53(11):1780-1790. doi: 10.1002/eat.23353. Epub 2020 Jul 28. PMID: 32720399. [PubMed].

7. Chakraborty K, Chatterjee M. Psychological impact of COVID-19 pandemic on general population in West Bengal: A cross-sectional study. Indian J Psychiatry 2020;62:266-72.

8. Everts J. Announcing Swine Flu and the Interpretation of Pandemic Anxiety. Antipode. 2013 Sep;45(4):809-825. doi: 10.1111/j.1467-8330.2012.01021.x. Epub 2012 Jul 19. PMID: 32313327; PMCID: PMC7161815.[PubMed].

9. Xie XF, Stone E, Zheng R, Zhang RG. The 'Typhoon Eye Effect': determinants of distress during the SARS epidemic. J. Risk Res. 2011 1;14(9):1091-107. 


\section{Tables}

TABLE 1 DISTRIBUTION OF STUDY PARTICIPANTS ACCORDING TO IMPACT ON PSYCHOSOCIAL HEALTH DUE TO ON-GOING COVID -19 PANDEMIC ( $\mathrm{N}=450)$

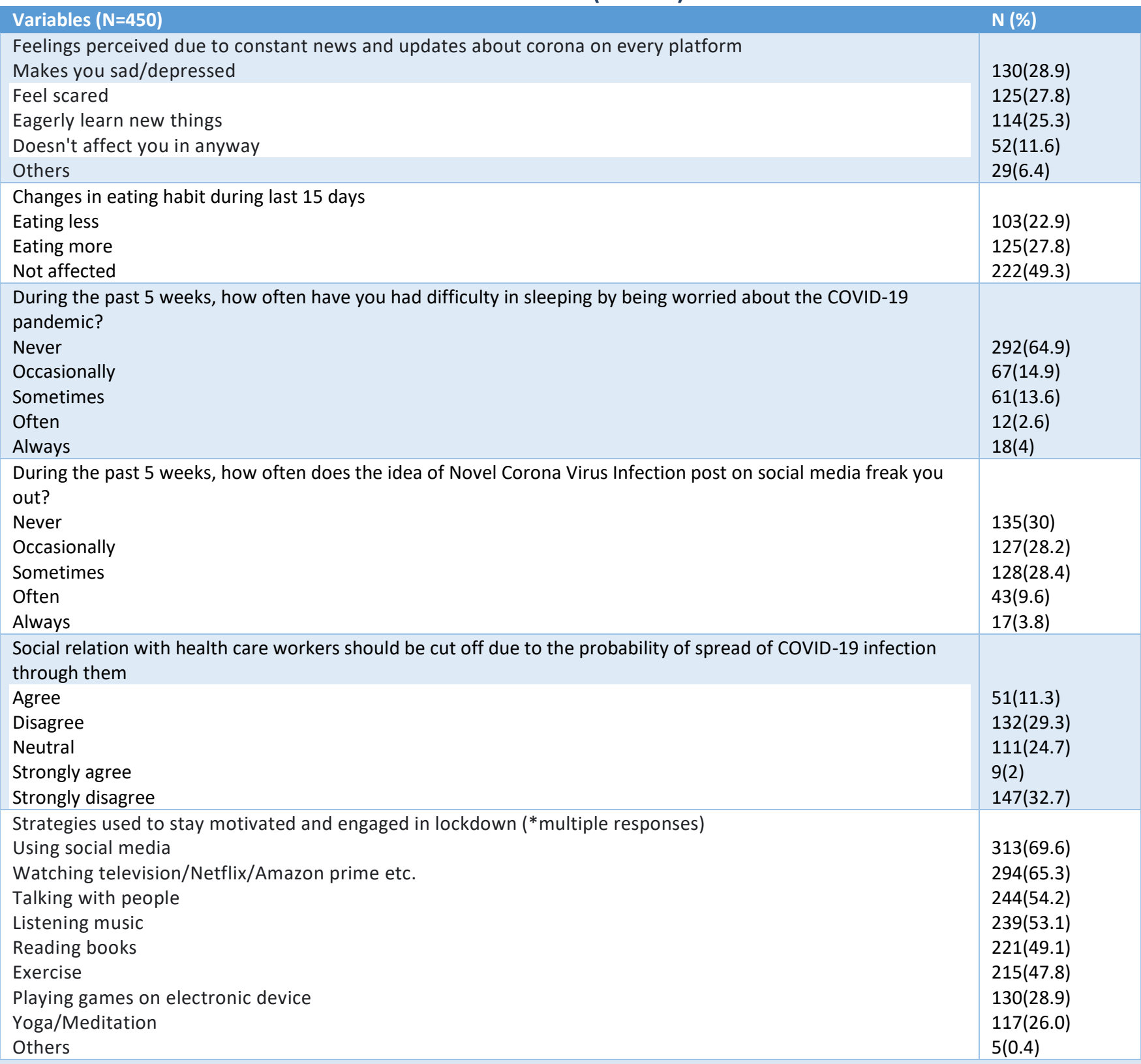

\section{Figures}

FIGURE 1 STATE WISE DISTRIBUTION OF STUDY PARTICIPANTS (IN PERCENTAGES) ( $\mathrm{N}=450$ )

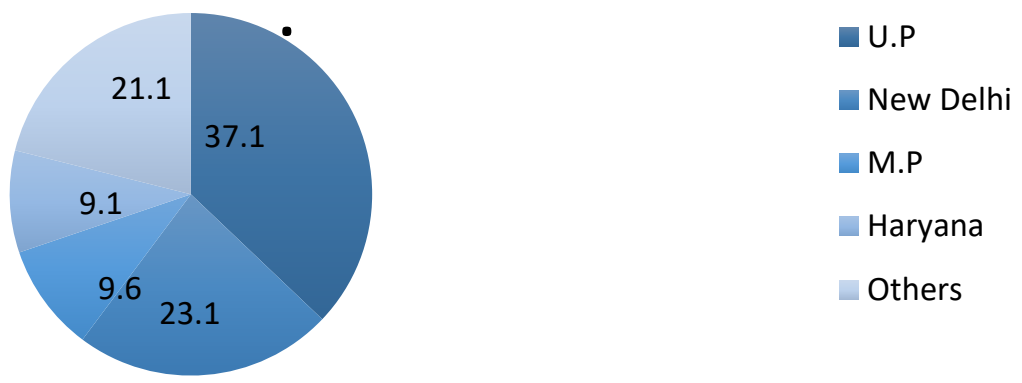

